\title{
PRIMER REGISTRO DE Entamoeba coli EN Amazona aestiva xanthopteryx (LORO HABLADOR CHAQUEÑO) EN ARGENTINA.
}

\author{
First record of Entamoeba coli in Amazona aestiva xanthopteryx (chaco's speaking \\ parrot) in Argentina.
}

\section{Artículo de Investigación}

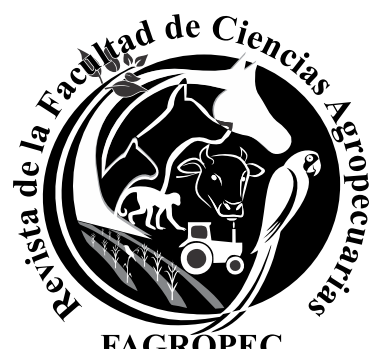

Recibido 15 de enero de 2020. Aceptado 3 de marzo de 2020.

${ }^{1}$ Profesor Asociado, Cátedra de Zoología, Diversidad y Ambiente, Facultad de Ciencias Veterinarias, Universidad Nacional del Litoral. Kreder 2805, (3080) Esperanza, Santa Fe, Argentina. Veterinario, Estación Biológica La Esmeralda, (3000) Santa Fe, Argentina.

iD https://orcid.org/0000-0002-0601-3166

${ }^{2}$ Master, Laboratorio de Análisis Clínico FCV UNL. Argentina.

Como citar:

SCIABARRASI, Antonio Alejandro y RUÍZ, Marcelo. Primer registro de Entamoeba coli en Amazona aestiva xanthopteryx (loro hablador chaqueño) en Argentina. En: Revista Facultad Ciencias Agropecuarias - FAGROPEC. Universidad de la Amazonia, Florencia Caquetá. Volumen 12 enero-junio, 2020. Pp. 2832. IS S en Línea: 2539-178X. https://doi.org/10.47847/fagropec.v12n1a2

*Autor para Correspondencia: asciabarrasi@fcv.unl.edu.ar
Antonio Alejandro Sciabarrasi ${ }^{1} *$ y Marcelo Ruíz ${ }^{2}$

\section{RESUMEN}

Las amebas de vida libre son microorganismos presentes en diferentes ambientes como el agua o el suelo, se mantienen en los ecosistemas y pueden producir graves enfermedades, en razón a su capacidad para portar a sus huéspedes bacterias intracelulares que son resistentes a la fagocitosis y que posteriormente invaden causando enfermedad bacteriana, lo que las convierte en un importante vehículo de trasmisión de diversas patologías de interés en salud pública. Para la investigación se recolectaron muestras fecales de un Amazona aestiva xanthopteryx (loro hablador del chaco) con signos de diarrea que fueron procesadas mediante métodos parasitológicos directos y de sedimentación espontánea. Para bacteriología se remitieron hisopados de la zona cloacal realizándose posteriormente siembras directas. Con el análisis de las muestras se identificó la presencia de Entamoeba coli como registro inédito para la especie, que aporta al conocimiento de esta problemática, más aún con la presencia de Escherichia coli en el cuadro clínico.

Palabras claves

Psitácidos, Zoonosis, amebas, diarrea, tenencia ilegal.

\begin{abstract}
Free-living amoebas are microorganisms present in different environments such as water or soil. They are maintained in ecosystems and can cause serious diseases due to their ability to carry intracellular bacteria to their hosts that are resistant to phagocytosis. Afterwards they invade causing bacterial disease, which makes these microorganisms an important vehicle of transmission of various pathologies of interest in public health. For this investigation, the fecal samples with signs of diarrhea were collected from an Amazona aestiva xanthopteryx (speaking parrot from chaco) and were processed by direct parasitological and spontaneous sedimentation methods. Swabs from the sewage area were sent to bacteriology and then direct seeding was carried out. With the help of the analysis of the samples, the presence of Entamoeba coli was identified as an unpublished record for the species. This study contributed to the knowledge of this problem, especially with the presence of Escherichia coli in the clinical picture.
\end{abstract}

Key words

Psittacids, Zoonoses, amoebas, diarrhea, illegal possession. 


\section{INTRODUCCIÓN}

Los parásitos son indicadores de la degradación y antropización ambiental (Bunbury et al. 2018). Los parásitos de las aves siempre han sido de interés veterinario tanto sanitario como productivo, en principio para el área de producción de aves de corral y actualmente en aves de compañía o de la clínica de mascotas no convencionales o silvestres. En Argentina, las investigaciones en aves silvestres son esporádicas y sujetas a eventuales hallazgos (Hinojosa y González, 2015), resultando el conocimiento científico relacionado, escaso y disperso, más aún para temas específicos como los protozoarios de psitácidos.

Para las aves en Argentina, se han identificado diversos registros de parásitos gastrointestinales en diferentes aviarios del país (Martínez et al, 2013; Sciabarrasi y Gervasoni, 2015), sin indicación de protozoarios del género Entamoeba como factores asociados.

Resulta importante en estas aves los factores que pueden favorecer la contaminación con formas parasitarias tales como las condiciones higiénicas del lugar, el hacinamiento, la alimentación, etc., más aún si la principal vía de transmisión parasitaria gastrointestinal es la fecal oral, donde el agua, alimento, presencia de moscas y/o manos de los operarios podrían convertirse en vectores mecánicos de estos parásitos (Barriga, 2016).

Para el país se ha identificado la distribución de cuatro especies de loros de género Amazona sp., siendo el Amazona aestiva xanthopteryx (loro hablador chaqueño o argentino) el más traficado, principalmente en estado de por su gran aprecio social como ave de jaula (Narosky y Yzurieta, 2015).

La separación de un animal de su entorno natural y estructura social, origina condiciones de estrés y disminución de su inmunocompetencia, lo que puede provocar que cuadros leves de parasitismo en su entorno natural se transformen en manifestaciones más intensas en condiciones de cautividad. Lo cual resulta preocupante en razón a la necesidad de A considerar la posibilidad de ocurrencia de infecciones de carácter zoonótico ya que se estima que el $75 \%$ de las enfermedades humanas emergentes tendrían tener conexión con animales silvestres (Bunbury et al. 2018).

Las Entamoebas, como importantes vehículos de trasmisión de diversas patologías, son raras de hallar en loros. La principal ameba parásita que se ha identificado en el intestino grueso de diferentes animales es la Entamoeba histolytica, reconocido patógeno causal de la disentería amebiana, la colitis amebiana, diarreas severas y el absceso hepático, que se puede transmitir por el agua, particularmente en áreas tropicales. Los quistes que varían entre 10 y $20 \mu \mathrm{m}$, salen en las heces y su propagación se deben a la contaminación fecal. La Entamoeba coli, apatógena, está distribuida en todo el mundo y se transmite a través de alimentos y agua contaminados (Jonnalagadda y Bhat, 2014), si bien es un protozoario no parásito, se puedo asociar a bacterias intracelulares como la Escherichia coli (Smirnov y Brown, 2014).

Por todo, el objetivo del presente trabajo fue registrar la presencia de Entamoeba coli en un psitácido ilegalmente mantenido en cautiverio como mascota, proporcionando información inédita que aporte al conocimiento de esta problemática en el loro hablador del chaco. 


\section{MATERIALES Y MÉTODOS}

El presente trabajo se realizó en la Estación de Rescate, Rehabilitación y Reubicación de Fauna "La Esmeralda de la Provincia de Santa Fe en Argentina, ubicación 31 35'12.9"S 6041'32.1"W, durante el mes de Marzo de 2019. Se utilizó un individuo adulto de edad superior a los 4 años, según la coloración del iris, y de sexo hembra, resultado obtenido del ADN en plumas (Figura 1). El ave objeto de estudio, procedía de un decomiso por tenencia ilegal de fauna realizado en la provincia de Santa Fe. Antes de iniciar el proceso habitual de cuarentena, el espécimen registró un pesos de $300 \mathrm{~g}$ (peso promedio habitual para las hembras $430 \mathrm{~g}$ ) y diarrea color verde con deyecciones en una frecuencia anormal de más de 20 por día (Calnek, 2015).

Una vez ingresada a la cuarentena recibió una

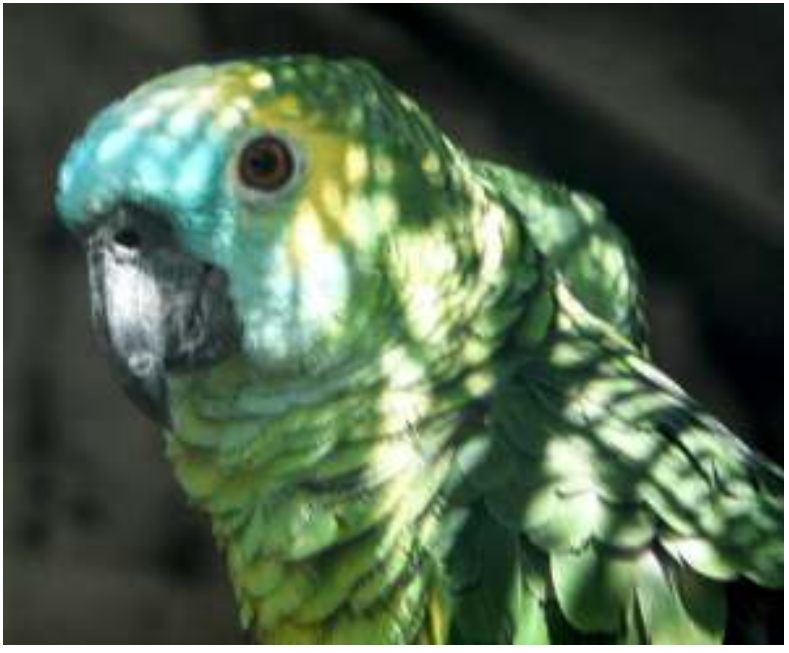

Figura 1.

Individuo adulto de Amazona aestiva xanthopteryx, objeto del estudio.

dieta balanceada de frutas y granos, dos veces al día (mañana y tarde).

Durante tres días no consecutivos fueron recolectaron muestras fecales, para posteriores estudios parasitológicos. Simultáneamente, se remitieron hisopados de la zona cloacal del ave para la realización de siembras directas para diagnóstico de bacterias. Las derivadas a estudios parasitológicos se trasportaron en potes colectores que fueron enviadas al Laboratorio de análisis clínico de la Facultad de Ciencias Veterinarias de la Universidad Nacional del Litoral de Argentina (FCV-UNL), en donde las muestras de heces fueron procesadas empleándose el método directo (Scholtens et al. 1998), el método de Willis o de flotación con solución saturada de sacarosa y con solución saturada de cloruro de sodio (Amaral et al. 1995) y el método de sedimentación espontánea (Greve et al. 1978).

\section{RESULTADOS Y DISCUSIONES}

Los animales silvestres son hospederos de una gran variedad de parásitos, muchos de los cuales registran potencialidad como agentes de zoonosis (Siemering, 2017). En las tres muestras analizadas parasitológicamente, se evidenció la presencia de Entamoeba coli con quistes esféricos y ovales (Figura 2), identificada como el primer registro del microorganismo para esta especie de ave psitaciforme en el país, que difiere del reporte de Figueroa Lyra et al. (2015), en su estudio en aves Psitaciformes en cautiverio en el estado de Pernambuco, Brasil, quienes reportaron una prevalencia de $0 \%$ del protozoario; y de los reportados por Graczyk et al. (2018), quienes identificaron una frecuencia de Entamoeba coli del 29,33\% en la avifauna de Brasil. El incremento en el registro de la presentacia del protozoario en aves, podría indicar su éxito como agente oportunista, y el riesgo de transmisión a los humanos, particularmente aquellos en mayor exposición como comerciantes y 

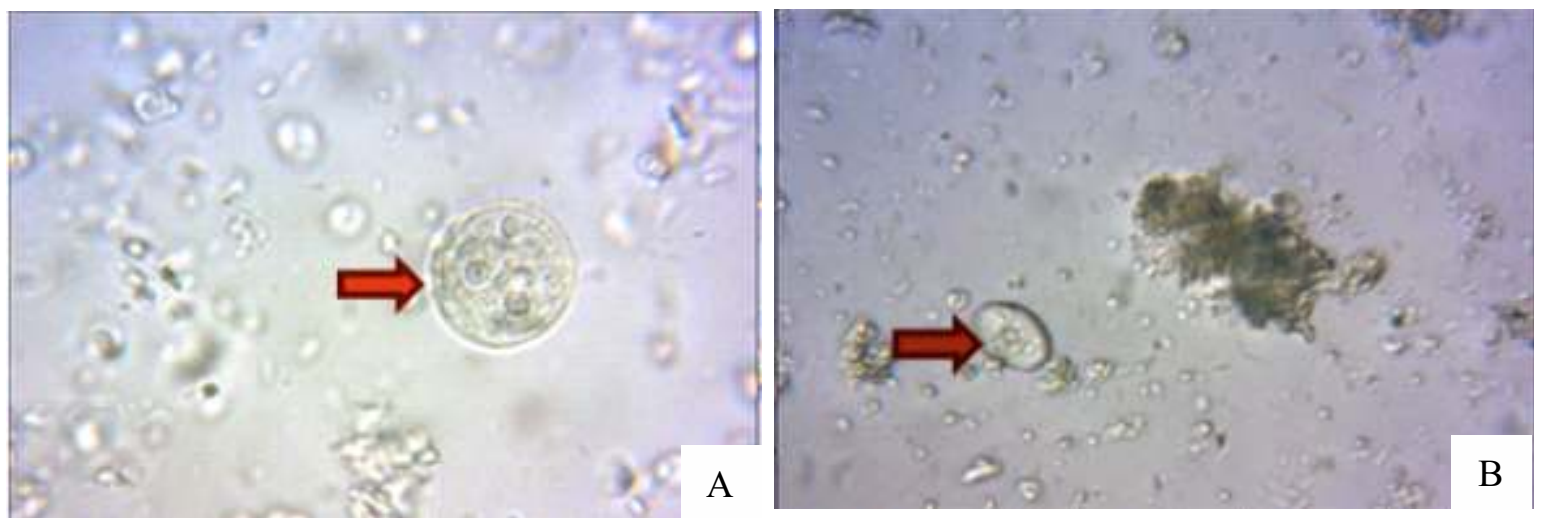

Figura 2.

Entamoeba coli. Quistes esféricos (A) y ovoides (B), de entre 20 y 24 micras. Observada (A) en 1000 aumentos (100X en inmersión) totales y (B) en 400 totales (40X).

tenedores ilegales, y profesionales vinculado con su menejo posdecomiso (Soares et al. 2018), en quienes es considerado aún apatógeno comensal del intestino (Graczyk et al. 2018).

Para los estudios bacteriológicos, concluida la siembra directa, se identificó el desarrollo de una enterobacteria coliforme compatible con Escherichia coli, bacteria de gran incidencia en aves en situación de hacinamiento, mal cautiverio y estrés (Banach et al. 2014).

\section{CONCLUSIONES}

Este primer registro de presencia de Entamoeba coli asociada a diarrea en un ave psitaciforme de la especie Amazona aestiva xanthopteryx, adquiere gran importancia en relación a constiuir evidencia del éxito adaptativo del microorganismo, y la posibilidad de su transmisión al hombre, situación con que complejiza con la indicación de presencia de Escherichia coli asociada al cuadro clínico. Resulta por lo anterior fundamental de desarrollo de investigaciones relacionadas, para la inclusión de un mayor número de especímenes objetivo de estudio con el fin de garantizar la videz estadística de los resultados.

\section{LITERATURA CITADA}

AMARAL, Leonardo; GONCALVES, Ivan y ZEFERINO, Sandra. Parasitologia de animais silvestres. In: XIX Congresso brasileiro e ii encontro internacional de zoológicos, Foz do Iguacu. Paraná Brasil, 1995. p.1.

BANACH, S., et al. Molecular typing of avian pathogenic Escherichia coli (APEC) from turkey poults. En: American Society for Microbiology General Meeting. Idaho, USA 2014.

BARRIGA, Omar. Las enfermedades parasitarias de los animales domésticos en la América Latina. Santiago de Chile: Editorial Germinal, 2016.247 Pp.

BUNBURY, Nancy, et al. Epidemiology and conservation implications of Trichomona gallinae infection in the endangered Mauritian pink pigeon. En: Biological Conservation, vol. 141, nor. 1, 2018. p. 153 -161. 
CALNEK, B. Enfermedades de la Aves. 5ª Edición, México D.F. : El Manual Moderno, México, D.F. 2015.

FIGUEIROA, Lyra, et al. (2015). Parásitos gastrointestinales de aves silvestres en cautiverio en el estado de Pernambuco. En: Parasitol Latinoam, Brasil. Vol. 57, 2015, p. 50-54

GRACZYK, Thaddeus; MAJEWSKA, Anna y SCHWAB, Kellogg The role of birds in dissemination of human waterborne enteropathogens. En: Trends in Parasitology, Vol. 24, nor. 2, 2018. p. 55-59.

GREVE, J., SAKLA, A., MCGEHEE, E. Bilharziasis in nanday conure. En: J Am Vet Med Assoc; Vol. 172, 1978, p. 1212-4.

HINOJOSA, S., y GONZÁLEZ, D. Current state of knowledgments of helmints in Chilean wild birds. En: Gayana, Vol. 69, 2015.p.241-253.

JONNALAGADDA PR, BHAT RV. (2014). Parasitic contamination of stored water used for drinking/cooking in Hyderabad. En: J Trop Med Publ Health. South Asian. Vol. 26, 2014, p.789-794.

MARTINEZ, F., et al (2013). Infestación por Capillaria y Ascaridia spp em Psitácidos de criadero. En: Ver. Med. Vet. Vol. 80, nor. 1, 2013, p. 24-26.

NAROSKY, Tito y YZURIETA, Darío. Aves de Argentina y Uruguay, Guía de identificación /Birds of Argentina \& Uruguay, a Field Guide (en español/inglés) (16 edición). Buenos Aires: Vázquez Mazzini editores. 2015.p. 432. ISBN 978-987-9132-27-2.

SCHOLTENS R G, NEW J C, JOHNSONS S. The nature and treatment of giardiasis in parakeets. En: J Am Vet Med Assoc, Vol,180, nor. 2, 1982, p. 3. - 170

SCIABARRASI, A. y GERVASONI, S. Parásitos gastrointestinales hallados en Psitaciformes de la Estación Zoológica Experimental "Granja la Esmeralda", Santa Fe, Argentina. II Congreso de Cría de Psitácidos. Belén de Escobar, Bs As. - Argentina. 2015.

SIEMERING, H. Zoonose. IN: FOWLER, Miller (Edit). Zoo and Wild Animal Medicine. California: Saunders Company. 2017. p. 64-8.

SMIRNOV, Alexey y BROWN, Susan. (2014). Guide to the methods of study and identification of soil gymnamoebae. En: Protistology, Department of Invertebrate Zoology, Faculty of Biology and Soil Sciences, St. Petersburg State University, Rusia. Vol. 148, 2014. 190.

SOARES, C., OLIVEIRA, J., y BRITO, M. Infeccao Natural por Entamoeba histolytica Schaudinn, 1903 em Euphractus sexcinctus (tatu mantidos em cautiveiro. En: Arq Brás Méd Vet Zoot; Vol. 52, 2018, p. 208-209. 